\title{
RESEARCH
}

Open Access

\section{Bioelectrical impedance analysis-guided fluid management promotes primary fascial closure after open abdomen: a randomized controlled trial}

Kai Wang ${ }^{1}$, Shi-Long Sun ${ }^{1}$, Xin-Yu Wang ${ }^{1}$, Cheng-Nan Chu', Ze-Hua Duan', Chao Yang ${ }^{1}$, Bao-Chen Liu', Wei-Wei Ding ${ }^{1,2^{*}}\left(\mathbb{D}\right.$, Wei-Qin $\mathrm{Li}^{1}$ and Jie-Shou $\mathrm{Li}^{\mathrm{i}^{*+}}$

\begin{abstract}
Background: Fluid overload (FO) after resuscitation is frequent and contributes to adverse outcomes among postinjury open abdomen (OA) patients. Bioelectrical impedance analysis (BIA) is a promising tool for monitoring fluid status and FO. Therefore, we sought to investigate the efficacy of BIA-directed fluid resuscitation among OA patients.

Methods: A pragmatic, prospective, randomized, observer-blind, single-center trial was performed for all trauma patients requiring OA between January 2013 and December 2017 to a national referral center. A total of 140 postinjury OA patients were randomly assigned in a 1:1 ratio to receive either a BIA-directed fluid resuscitation (BIA) protocol that included fluid administration with monitoring of hemodynamic parameters and different degrees of interventions to achieve a negative fluid balance targeting the hydration level $(\mathrm{HL})$ measured by BIA or a traditional fluid resuscitation (TRD) in which clinicians determined the fluid resuscitation regimen according to traditional parameters during 30 days of ICU management. The primary outcome was the 30-day primary fascial closure (PFC) rate. The secondary outcomes included the time to PFC, postoperative 7-day cumulative fluid balance (CFB) and adverse events within 30 days after OA. The Kaplan-Meier method and the log-rank test were utilized for PFC after OA. A generalized linear regression model for the time to PFC and CFB was built.

Results: A total of 134 patients completed the trial (BIA, $n=66$; TRD, $n=68$ ). The BIA patients were significantly more likely to achieve PFC than the TRD patients ( $83.33 \%$ vs. $55.88 \%, P<0.001)$. In the BIA group, the time to PFC occurred earlier than that of the TRD group by an average of 3.66 days $(P<0.001)$. Additionally, the BIA group showed a lower postoperative 7-day CFB by an average of $6632.80 \mathrm{ml}(P<0.001)$ and fewer complications.

Conclusion: Among postinjury OA patients in the ICU, the use of BIA-guided fluid resuscitation resulted in a higher PFC rate and fewer severe complications than the traditional fluid resuscitation strategy.
\end{abstract}

\footnotetext{
* Correspondence: dingwei_nju@hotmail.com; njijieshou@126.com

${ }^{+}$Wei-Wei Ding and Jie-Shou Li contributed equally to this work.

'Division of Trauma and Surgical Intensive Care Unit, Research Institute of General Surgery, Jinling Hospital, Medical School of Nanjing University,

Nanjing 210002, No. 305 East Zhongshan Road, Nanjing 210002, Jiangsu,

China

Full list of author information is available at the end of the article
}

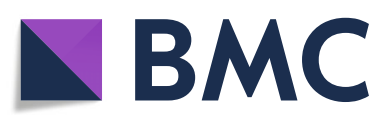

(- The Author(s). 2021 Open Access This article is licensed under a Creative Commons Attribution 4.0 International License, which permits use, sharing, adaptation, distribution and reproduction in any medium or format, as long as you give appropriate credit to the original author(s) and the source, provide a link to the Creative Commons licence, and indicate if changes were made. The images or other third party material in this article are included in the article's Creative Commons licence, unless indicated otherwise in a credit line to the material. If material is not included in the article's Creative Commons licence and your intended use is not permitted by statutory regulation or exceeds the permitted use, you will need to obtain permission directly from the copyright holder. To view a copy of this licence, visit http://creativecommons.org/licenses/by/4.0/. The Creative Commons Public Domain Dedication waiver (http://creativecommons.org/publicdomain/zero/1.0/) applies to the data made available in this article, unless otherwise stated in a credit line to the data. 
Keywords: Trauma, Open abdomen, Fluid overload, Fluid resuscitation, Primary fascial closure, Bioelectrical

impedance analysis

\section{Background}

Open abdomen (OA) has been accepted as a therapeutic option for managing abdominal catastrophes over the last two decades [1-4]. However, OA patients have a high risk of developing various disastrous complications [5-7]. Promoting primary fascial closure (PFC) may reduce complications and improve outcomes $[8,9]$. Historically, early aggressive crystalloid administration during intensive care unit (ICU) management resulted in fluid overload (FO) and continuing visceral edema [10, 11], which is a contributing factor of failure to achieve PFC [12-15]. Moreover, FO was linked to adverse outcomes in critically ill patients $[16,17]$. Recently, crystalloid modulated and restrictive fluid resuscitation that avoids FO, including PRospective Observational Multicenter Major Trauma Transfusion (PROMMTT) study, balanced and damage control resuscitation, have been proved to achieve excellent results in trauma patients [18-21]. Reduction of resuscitation fluid volumes in OA patients was associated with an increased PFC rate during hypertonic saline, goal directed and direct peritoneal resuscitation [22-25]. Besides, our center also confirmed an association between FO and delayed PFC [26]. Therefore, judicious ICU fluid resuscitation therapy targeting assessment of FO to promote PFC is of great significance.

Traditionally, the FO calculation method was based on fluid balance measurements and body weight variations in critically ill patients. However, fluid balance studies using the difference in fluid inputs and outputs do not include insensible water loss and are less accurate [27, 28]. Moreover, it is difficult to measure body weight precisely in the ICU, and the value may change for reasons other than fluid infusion [29], which suggests the need for more convenient, reliable and accurate tools.

Bioelectrical impedance analysis (BIA) technology measures the total body, regional or segmental impedance of tissues and is derived from resistance (R) and reactance $(\mathrm{Xc})$ by the transmission of electric currents at different frequencies [30, 31]. Rapid changes in hydration and soft tissue mass are identified by measurements standardized for height. This rapid, noninvasive, and convenient approach was reliable for ICU patients in whom the FO calculation was recorded using conventional methods [32]. The BIA technique appears to be valid, especially for assessment of FO by repeated measurements.

Therefore, we performed the trial to investigate the effects of fluid resuscitation protocols with adjustment determined according to the hydration level measured by BIA in compared with the traditional fluid resuscitation strategy determined by clinicians according to usual clinical parameters among OA patients. Our study hypothesis was that application of BIA to assess the hydration status among postinjury OA patients during ICU resuscitation could decrease fluid overload, promote PFC, and reduce complications caused by fluid overload.

\section{Methods}

\section{Study design}

The Bioelectrical impedance analysis-Guided Fluid Management (BGFM) was a pragmatic, prospective, randomized, observer-blind, single-center trial (clinicaltrials.gov Identifier: NCT03466684) conducted in two parallel groups (Fig. 1). This study was approved by the Institutional Ethics Committee of Jinling Hospital, Medical School of Nanjing University (No. 2012NZGKJ-096). Written informed consent was obtained from all participants or the closest relative of each participant after ICU admission. Patients were enrolled in the study between January 2013 and December 2017. The end of follow-up occurred in March 2018.

\section{Study setting}

This study was set at the Research Institute of General Surgery of Jinling Hospital in Nanjing, Jiangsu, China. This national referral center has two Surgical Intensive Care Units (SICUs) that provide trauma and acute critical care surgery (ACCS) services for eastern China. After an abbreviated laparotomy, trauma patients with nonclosure of the abdominal fascia were admitted to the SICU.

\section{Study participants}

Severely-injured adult patients admitted to SICU with OA who underwent emergent abbreviated laparotomy were considered eligible. The OA was defined as nonclosure of the abdominal fascia and skin after laparotomy that required temporary abdominal closure (TAC) [33]. The decision to perform OA was at the discretion of the attending physician and was made primarily for damage and abdominal contamination control, hemorrhage or planned re-laparotomy according to the damage control surgery (DCS) concept.

The TAC method was standardized among all available patients. TAC at the initial operation was performed with a vacuum-assisted and mesh-mediated fascial traction (VAWCM) as described previously [26, 


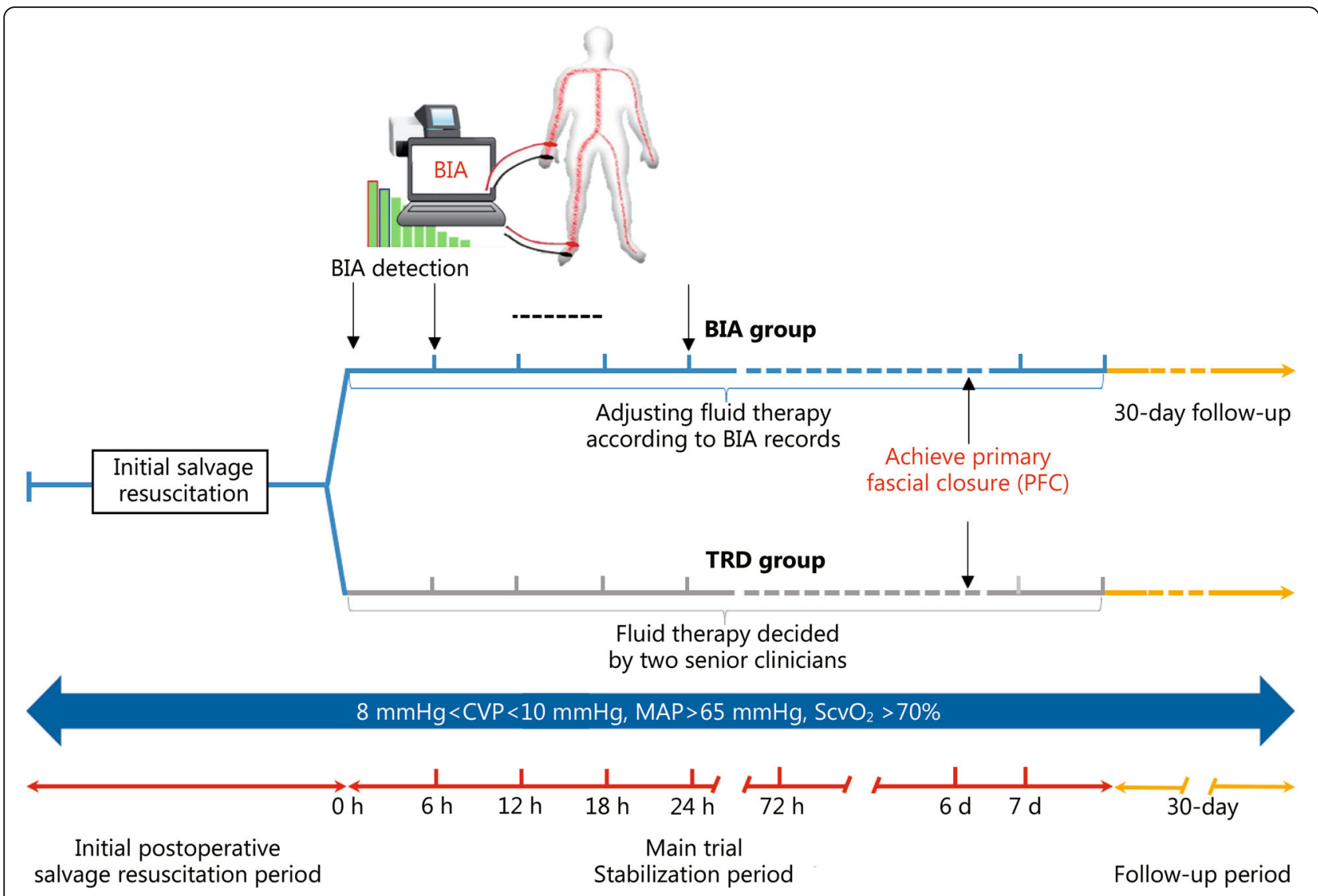

Fig. 1 Trial design, the pragmatic, prospective, randomized, observer-blind, single-center trial had a duration of 7 days and a 30-day follow-up period. The patients were randomly assigned to two groups, and the different interventions were implemented accordingly. CVP central venous pressure, MAP mean arterial pressure, $\mathrm{ScvO}_{2}$ central venous oxygen saturation

34]. In brief, we placed a sterile perforated plastic sheet intra-abdominally to cover the viscera and sutured the oval-shaped polypropylene mesh (Prolene; Ethicon, Johnson \& Johnson, Somerville, NJ) to the fascial edge with a running 0 monofilament suture. Besides, sterile gauze and moist laparotomy pads were placed to protect fascia and subcutaneous tissue and two silicone drain tubes were brought in caudally through the skin over the gauze. The drains were linked to a suction device with continuous topical negative pressure (100-150 $\mathrm{mmHg})$. Next, the patients were taken back to the operating room every 2 days to achieve fascial closure. If possible, the abdominal wall was closed. Otherwise, we cut the mesh in the midline, changed the inner plastic sheet and gauze, and tightened the mesh by suturing it in the midline with a running 0 monofilament suture. The TAC was changed every 2 days. We decided to close the abdomen when the edge of the fascia is only $3-5 \mathrm{~cm}$ away with week tension assessed by pulling the fascial edges toward the midline. Finally, we removed the mesh, and closed the fascia, followed by skin closure. If the abdomen could not be closed after attempts within 15 days, then the abdomen was closed with biologics or skin grafting with a subsequent planned ventral hernia at the discretion of the senior clinicians $[4,35]$.

The exclusion criteria were as follows: a) age less than 18 years; b) pregnancy; c) lactation; d) limb amputations; e) mental disorders; f) diabetes mellitus; g) pre-existing blood disorders; h) pre-existing abdominal fistulas; i) pre-existing terminal illness; $\mathrm{j}$ ) liver dysfunction (ChildPugh class C); k) New York Heart Association (NYHA) class IV; l) chronic renal failure requiring dialysis; $\mathrm{m}$ ) therapy with an extracorporeal membrane oxygenator (ECMO); $\mathrm{n}$ ) enrolled in an ongoing, interventional randomized controlled trial (RCT); and o) expected to die within $24 \mathrm{~h}$ of ICU admission due to devastating injuries.

\section{Randomization}

For patient allocation, a computer-generated randomization list gave an allocation table in permuted blocks (fixed block size, 4; allocation ratio, 1:1). Allocation concealment was conducted at the bedside using a 
sealed envelope to allow randomization by blinded administrative assistants immediately after the participant was deemed eligible.

\section{Study treatments}

Eligible patients were randomly allocated to the traditional fluid resuscitation group (defined as TRD) or BIA-directed fluid resuscitation group (defined as BIA). After allocation, a multifrequency BIA with eight tactile electrodes (Inbody S10 Biospace, Biospace Co. Ltd., Seoul, Korea) was used to assess the body fluid status every $6 \mathrm{~h}$ within the first $72 \mathrm{~h}$ after admission to the ICU and daily for 4 days in both groups.

An alternating current of $250 \mathrm{~mA}$ at the frequency bands of $5,50,250$, and $500 \mathrm{kHz}$ was used, and two electrodes were built into every grip and plate as singlefrequency BIA with eight electrodes. The patient's skin was cleaned with saline before applying the electrodes to the arm and leg. The segmental impedance values in the arm, leg, and trunk were measured using a multifrequency analyzer for all frequencies. The hydration level (HL), fat mass (FM), body cell mass (BCM), internal cell water $(\mathrm{ICW})$, external cell water (ECW), and regional fluid distribution were measured and automatically displayed. The HL and total body hydration status indices are evaluated by resistance and reactance through BIA. The migration of the vector in the nomogram results in variations of the numerical value of the HL. The OA patients were stratified into three hydration level categories (dehydrated, normally hydrated and hyperhydrated). According to the numerical scale for BIA, normal hydration was between 72.7 and $74.3 \%$. Higher and lower values represented states of hyperhydration and dehydration, respectively. Hyperhydration was classified into three categories as follows: mild (74.3-81.0\%), moderate (81.1-87.0\%), and severe (> 87.0\%) [36]. Similarly, dehydration was also classified into three categories: mild (71.1-72.7\%), moderate (69.1-71.0\%), and severe ( $\leq$ 69.0\%) [16]. Trained nursing staff performed all anthropometric measurements.

First, all patients received aggressive hemodynamic support according to the standard protocol in our department during initial salvage resuscitation. Briefly, a $500-\mathrm{ml}$ bolus of crystalloid was applied every $30 \mathrm{~min}$ to maintain central venous pressure (CVP) of 8 to 10 $\mathrm{mmHg}$. If the mean arterial pressure (MAP) was below $65 \mathrm{mmHg}$, vasopressors were provided to maintain a MAP $\geq 65 \mathrm{mmHg}$. Red blood cells were transfused to promote $\mathrm{ScvO}_{2}$ when $<70 \%$. The colloid used for fluid resuscitation was mainly blood products. If the patients had hypoproteinemia, albumin would be applied. Persistent anuria was assessed by senior clinicians, but we did not use the urine output to guide intravenous fluid resuscitation. When the patient CVP, MAP, and $\mathrm{ScrO}_{2}$ parameters met the above requirements, the patients were committed to the next stabilization period directed by the two fluid resuscitation strategies described below. The end point of resuscitation was postoperative day 7 in ICU after OA.

In the TRD group, the patients received a restricted intravenous fluid regimen or dehydration therapy based on the decision made by two senior clinicians according to the cumulative fluid balance recording and hemodynamic condition, such as the heart rate, blood pressure, CVP, MAP, urine output, cardiac echocardiography, lactate and body weight changes. BIA information was not available to the clinicians managing the patients in the TRD group, nor adjusted during fluid restriction or pharmacological and mechanical therapy.

In contrast, in the BIA group, the protocol for patients who received BIA-directed resuscitation was as follows (Fig. 2). If hyperhydration ( $\mathrm{HL}>74.3 \%$ ) was found after achieving the CVP, MAP, and $\mathrm{ScvO}_{2}$ goals, then the following fluid management strategy was applied for each 6-h period. If the HL was above $87.0 \%$ (severe level), fluid infusion was restricted, a furosemide drip was used, and continuous renal replacement therapy (CRRT) was initiated with an ultrafiltration rate when the patients were in failure or had an inadequate response to the above diuretic therapy that gave a net negative fluid balance of at least $1500 \mathrm{ml}$ during the next $6 \mathrm{~h}$. If the HL was $81.1-87.0 \%$ (moderate level), the above methods were used to trigger a net negative fluid balance (approximately $1000 \mathrm{ml}$ ) for the next six h. Similarly, if the HL was 74.3-81.0\% (mild level), a net negative fluid balance of approximately $500 \mathrm{ml}$ was achieved during the next $6 \mathrm{~h}$ of ICU hospitalization. If the HL was below $71.0 \%$ (i.e., a state of dehydration), the CVP, MAP, and $\mathrm{ScvO}_{2}$ were maintained as described above during ICU resuscitation. Vasoactive agents were used if necessary combined with close monitoring of the cardiovascular response, and a net negative fluid balance was abandoned during periods of hemodynamic instability.

\section{Blinding}

Because implementation of the different fluid intervention regimens required clinician intervention, blinding of research clinicians participating in the protocol was inappropriate and infeasible. However, the other medical staff, sponsors, patients, and data and safety monitoring team remained unaware of the interventions during the trial.

\section{Data collection and outcomes measurements}

Demographic and clinical characteristics were systematically recorded, including age, gender, mechanism of injury, indication for the open abdomen, intervention, laboratory tests, complications, and day of hospital and 


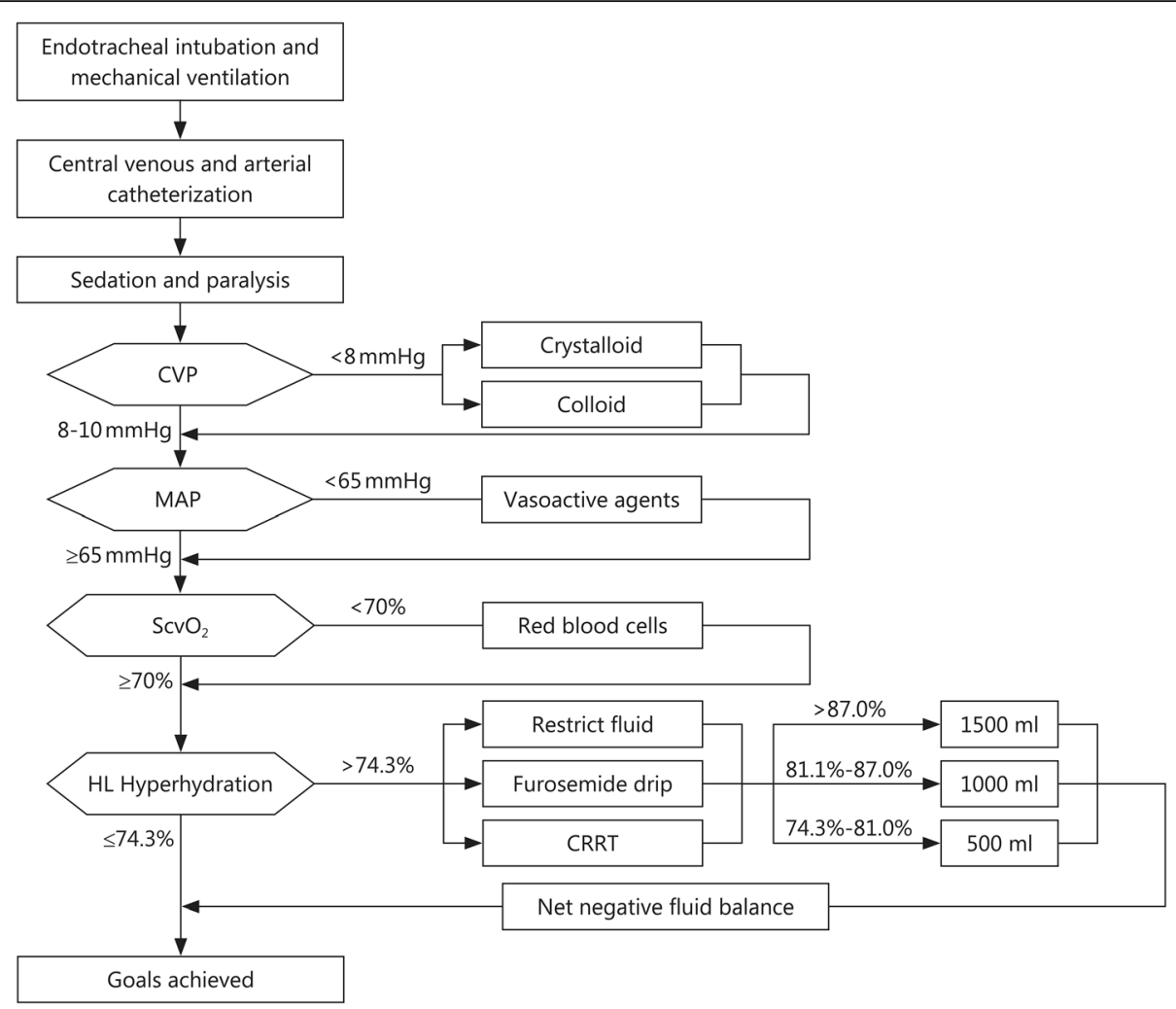

Fig. 2 Protocol for BIA-directed fluid resuscitation. CVP central venous pressure, MAP mean arterial pressure, $\mathrm{ScVO}_{2}$ central venous oxygen saturation, HL hydration level, CRRT continuous renal replacement therapy

ICU admission. Patient populations were classified as blunt or penetrating according to the injury mechanism. The illness severity was based on the Acute Physiology and Chronic Health Evaluation (APACHE) II score, Sequential Organ Failure Assessment (SOFA) score, Abbreviated Injury Score (AIS) and Injury Severity Score (ISS) for trauma patients.

The fluid resuscitation volumes for the patients were systematically collected for postoperative 7 days. The total fluid intake was accurately monitored, which included administration of blood products, intravenous fluids, and drug infusions and provision of various nutrition support, such as enteral and parenteral nutrition. The fluid output included the CRRT output, urine output, tube drainage output, actual blood loss, nasogastric feeding tube output, stool output, insensible perspiration from both the skin and respiratory tract, and fluid drainage from TAC dressings. The cumulative sum of total blood product transfusions in the first $24 \mathrm{~h}$, cumulative fluid balance and 24-h fluid balance over the first 7 days of OA management were recorded. During the first $72 \mathrm{~h}$ after OA, the vasopressors administered in the SICU were collected, including norepinephrine, vasopressin, phenylephrine, and dobutamine.
The primary outcome measured was the primary fascial closure rate $(100 \%$ direct approximation of abdominal fascial edges) within 30 days. The secondary outcomes measured included days to PFC, postoperative 7-day cumulative fluid balance, 30-day mortality, hospital and ICU length of stay (LOS), length of mechanical ventilation and complications within 30 days after OA. All patients were followed 30 days from enrollment, and the outcomes at hospital discharge were included.

\section{Sample size}

Postinjury OA patients with sIAI admitted to our referral center were anticipated to have a low fascial closure rate according to previous studies (almost 60\%) and similar studies in other centers $(33-60 \%)[26,33,37$. The fascial closure rate can exceed $80 \%$ with a 20 to $25 \%$ increase in intervention groups according to our previous pre-experiment trial. We estimated that an initial sample size of 120 would be required to detect a clinically significant 5\% increase in the PCF rate at $80 \%$ power. The sample size was increased to 140 by the data and safety monitoring board according to an anticipated loss of 5 to $10 \%$ of patients entering the study due to changes in scheduled resuscitation. 


\section{Statistical analysis}

Continuous data were analyzed using Student's t-test. Categorical data were analyzed using the Chi-square test or Fisher's exact test whenever appropriate. The Kaplan-Meier method and the log-rank test were utilized for primary fascial closure up to 30 days after OA. Trends in the daily fluid input, daily fluid output, daily fluid balance, and cumulative fluid balance were illustrated using GraphPad Prism (version 7.0 for Mac, GraphPad Software, La Jolla, CA, USA) as the means and 95\% confidence intervals (CIs) and compared using one-way ANOVA. A generalized linear regression model for the time until closure and $\mathrm{cu}$ mulative fluid balance was built, including the covariates of BIA usage and any covariates with $P<0.2$ in the statistical analyses. The data are reported as the means \pm standard deviations (SDs) and medians (lower quartile, upper quartile) for continuous variables and as percentages for categorical variables. A $P$ value of less than 0.05 was deemed statistically significant. The analyses were performed with the SAS statistical analysis software, version 9.3 (SAS Institute, Cary, NC).

\section{Results}

Between January 2013 and December 2017, a total of 160 patients undergoing OA with temporary abdominal closure were admitted to the two SICUs in our department. Of these patients, 20 were excluded (pre-existing abdominal fistulas, received prior therapy during ICU stay, age $<18$ years, advanced liver dysfunction, limb amputations, chronic renal failure requiring dialysis, or therapy with an ECMO). A total of 140 participants were randomized ( 4 and 2 patients were lost to follow-up or discontinued the intervention in the BIA and TRD groups, respectively), and 134 participants were treated (66 in the BIA group and 68 in the TRD group; Fig. 3). The demographic characteristics, illness severity, and BIA data of the two clinical groups were shown in Table 1. The indications for OA were similar for the two groups.

\section{Fascial closure}

All trauma patients with OA were taken back to the operating room for multiple abdominal operations before achieving fascial closure. The number of reoperations was similar between groups. The primary fascial closure

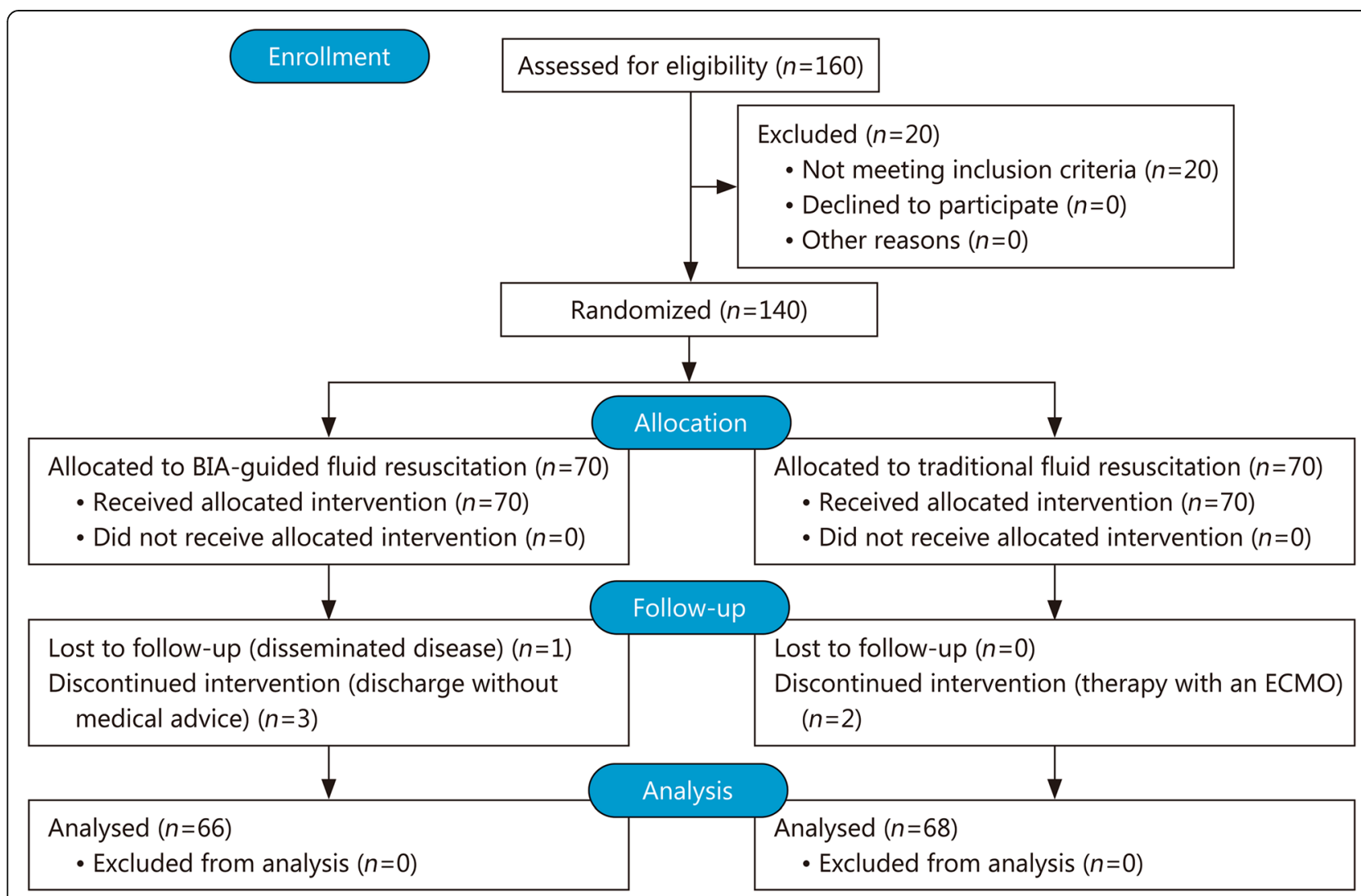

Fig. 3 Patient CONSORT (Consolidated Standards of Reporting Trials) flow chartBIA bioelectrical impedance analysis, CONSORT Consolidated Standards of Reporting Trials, ECMO extracorporeal membrane oxygenator. 
Table 1 Patient characteristics and perioperative data by study group

\begin{tabular}{|c|c|c|c|}
\hline Characteristic & BIA group $(n=66)$ & TRD group $(n=68)$ & $P$ value \\
\hline Age [years, mean \pm SD] & $46.60 \pm 11.80$ & $46.40 \pm 7.70$ & 0.904 \\
\hline Male, sex $[n(\%)]$ & $39(59.09)$ & $39(57.35)$ & 0.838 \\
\hline BMI $\left[\mathrm{kg} / \mathrm{m}^{2}\right.$, mean $\left.\pm \mathrm{SD}\right]$ & $24.00 \pm 3.10$ & $24.20 \pm 2.40$ & 0.663 \\
\hline Mechanism of injury [n (\%)] & & & 0.619 \\
\hline Blunt & $48(72.7)$ & $52(76.5)$ & \\
\hline Penetrating & $18(27.3)$ & $16(23.5)$ & \\
\hline AIS [mean $\pm S D]$ & $8.20 \pm 1.40$ & $7.90 \pm 1.50$ & 0.335 \\
\hline ISS [mean \pm SD] & $24.80 \pm 4.10$ & $23.90 \pm 3.60$ & 0.208 \\
\hline APACHE II [mean \pm SD] & $24.00 \pm 2.50$ & $23.50 \pm 2.60$ & 0.267 \\
\hline SOFA $[$ mean $\pm S D]$ & $10.10 \pm 2.30$ & $9.80 \pm 2.00$ & 0.362 \\
\hline Indication for open abdomen [n (\%)] & & & 0.944 \\
\hline Damage control & $29(43.94)$ & $30(44.12)$ & \\
\hline Intra-abdominal infections & $28(42.42)$ & $30(44.12)$ & \\
\hline ACS & $9(13.64)$ & $8(11.76)$ & \\
\hline Number of reoperations $[n$, mean $\pm S D]$ & $1.65 \pm 0.77$ & $1.90 \pm 0.88$ & 0.090 \\
\hline Intraoperative fluid balance $[\mathrm{ml}$, mean \pm SD] & $1480.60 \pm 511.20$ & $1394.90 \pm 585.50$ & 0.369 \\
\hline POD 1 blood products [U, mean \pm SD] & $10.05 \pm 4.00$ & $10.29 \pm 3.90$ & 0.714 \\
\hline Number of vasopressors $[n$, mean $\pm S D]$ & $2.35 \pm 0.97$ & $2.38 \pm 0.85$ & 0.830 \\
\hline Hydration level on admission to ICU $[\%$, mean \pm SD] & $79.60 \pm 3.30$ & $78.80 \pm 5.00$ & 0.233 \\
\hline POD 7 hydration level $[\%$, mean \pm SD] & $71.50 \pm 3.50$ & $76.70 \pm 3.70$ & $<0.001$ \\
\hline Mean value of hydration level $[\%$, mean $\pm S D]$ & $74.60 \pm 4.60$ & $78.40 \pm 4.50$ & $<0.001$ \\
\hline
\end{tabular}

BIA bioelectrical impedance analysis, TRD traditional fluid resuscitation, $B M I$ body mass index, AIS abbreviated injury score, ISS injury severity score, $A P A C H E ~ I /$ acute physiology and chronic health evaluation score II, SOFA sequential organ failure assessment, ACS acute compartment syndrome, SD standard deviation, POD postoperative day. ${ }^{*} P$-values less than 0.05 were considered as statistically significant

Table 2 Postoperative fluid balance, complications and patient outcomes

\begin{tabular}{|c|c|c|c|}
\hline Characteristic & BIA group $(n=66)$ & TRD group $(n=68)$ & $P$ value ${ }^{*}$ \\
\hline Primary fascial closure [n (\%)] & $55(83.33)$ & $38(55.88)$ & $<0.001$ \\
\hline Time to fascial closure [days, mean \pm SD] & $4.7 \pm 2.5$ & $8.6 \pm 2.5$ & $<0.001$ \\
\hline POD 7 cumulative fluid balance $[\mathrm{ml}$, mean \pm SD] & $4620.7 \pm 4532.0$ & $11,448.6 \pm 4749.1$ & $<0.001$ \\
\hline \multicolumn{4}{|l|}{ Intra-abdominal complications [n (\%)] } \\
\hline Superficial infection & $24(36.36)$ & $35(51.47)$ & 0.078 \\
\hline Intra-abdominal abscess/sepsis & 39 (59.09) & $45(66.18)$ & 0.397 \\
\hline Enteroatmospheric fistula & $3(4.55)$ & $21(30.88)$ & $<0.001$ \\
\hline \multicolumn{4}{|l|}{ Extra-abdominal complications [n (\%)] } \\
\hline Pneumonia & $20(30.30)$ & $39(57.35)$ & $0.002^{*}$ \\
\hline Sepsis & $26(39.39)$ & $38(55.88)$ & 0.056 \\
\hline Acute renal failure & $6(9.09)$ & $9(13.24)$ & 0.447 \\
\hline ALI & $2(3.03)$ & $15(22.06)$ & 0.002 \\
\hline \multicolumn{4}{|l|}{ Outcomes } \\
\hline Ventilator days [days, mean \pm SD] & $13.5 \pm 7.9$ & $20.8 \pm 8.1$ & $<0.001$ \\
\hline ICU LOS [days, mean \pm SD] & $19.7 \pm 6.9$ & $23.1 \pm 7.6$ & 0.006 \\
\hline Hospital LOS [days, mean \pm SD] & $23.9 \pm 7.1$ & $27.7 \pm 3.1$ & $<0.001$ \\
\hline 30-day mortality [n (\%)] & $9(13.64)$ & $16(23.53)$ & 0.142 \\
\hline
\end{tabular}

Data are expressed as the mean \pm SD for continuous variables, or percentage for categorical variables. BIA bioelectrical impedance analysis, $T R D$ traditional fluid resuscitation, $A L I$ acute lung injury, $I C U$ intensive care unit, $L O S$ length of stay, $P O D$ postoperative day, $S D$ standard deviation. ${ }^{*} P$-values less than 0.05 were considered as statistically significant 
rate was significantly higher in the BIA group than in the TRD group $(83.33 \%$ vs. $55.88 \%, P<0.001$; Table 2$)$. The median days to PFC were significantly lower in the BIA group than in the TRD group $[(4.7 \pm 2.5)$ days vs. (8.55 \pm 2.5$)$ days, $P<0.001]$. The cumulative incidence of PFC up to 30 days in the TRD group was significantly more likely to be delayed than that in the BIA group, which was more likely to be closed with a higher rate $(P<0.001$; Fig. 4).

After generalized linear regression analysis of the time to fascial closure was conducted to adjust for the admission diagnosis and prognostic factors (age, male sex, BMI, illness severity, indications, number of reoperations, number of vasopressors and intraoperative fluid volume), we found that resuscitation guided by BIA reduced the time to PFC by an average of 3.66 days (Table 3).

\section{Fluid resuscitation}

Intraoperatively, the fluid input, fluid output, and total fluid balance did not differ between the groups (Table 1, Table S1). The cumulative sum of total blood product transfusions at postoperative day (POD) 1 were similar between the two groups. Over the first 7 days after OA, the amount of fluid input was lower in the BIA group than in the TRD group at postoperative days (PODs) 15 and 7 but did not significantly differ at POD 6 (Fig. 5a, Table S1). Compared with that of the TRD group, the BIA group underwent more fluid output at PODs 2-4 (Fig. 5b, Table S1). The amount of fluid output differed but failed to reach significance at PODs 1 and 5-7. Fluid resuscitation directed by BIA resulted in a significantly lower amount of daily fluid balance at PODs $1-5$ and 7 (Fig. 5c, Table S1).

Over the 7 days of ICU resuscitation, the amount of cumulative fluid balance was lower in the BIA group at PODs 1-7 (Fig. 5d, Table 2, Table S1). Besides, HL was

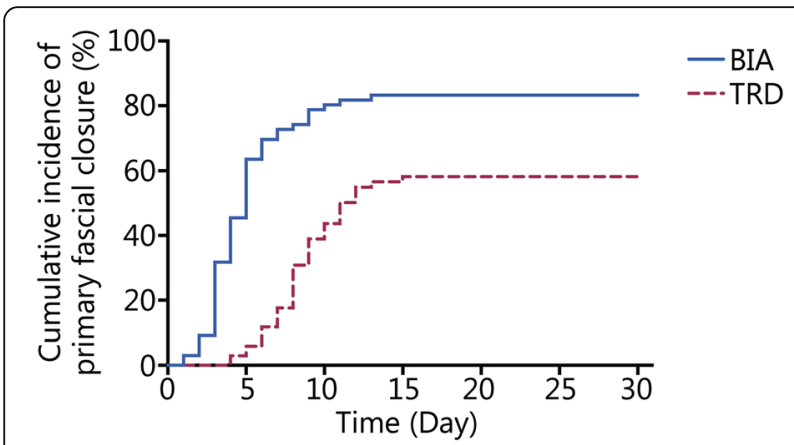

Fig. 4 Cumulative incidence of primary fascial closure. Patients resuscitated by TRD (red, dotted line) were more likely to be delayed than those in the BIA group, who were more likely to be closed with a high rate (blue, full line). BIA bioelectrical impedance analysis, ECMO extracorporeal membrane oxygenator lower in the BIA group at PODs 2-7 (Fig. 5e, Table 1). Generalized linear regression for the postoperative 7-day CFB performed with the admission diagnosis and prognostic factors (age, male sex, BMI, illness severity, number of reoperations, number of vasopressors and intraoperative fluid volume) showed that the BIA group had a lower postoperative 7-day CFB by an average of $6632.80 \mathrm{ml}$ (Table 3). More than two vasopressors were used per patient during ICU resuscitation, and the vasopressor requirements were similar between the two groups $(P=0.83$; Table 1$)$.

\section{Outcomes and complications}

Complications were not infrequent in the two groups (Table 2). An enteroatmospheric fistula (EAF) was significantly more likely to occur in patients undergoing TRD $(30.88 \%$ vs. $4.55 \%, P<0.001)$. Among the extraabdominal complications, patients resuscitated by TRD were also significantly more likely to have pneumonia (57.35\% vs. $30.30 \%, P=0.002$ ) and an acute lung injury (ALI) $(22.06 \%$ vs. $3.03 \%, P<0.001)$. Compared with the patients in the TRD group, their BIA counterparts had fewer ventilator days $[(13.5 \pm 7.9)$ days vs. $(20.8 \pm 8.1)$ days, $P<0.001]$, shorter ICU lengths of stay [(19.7 \pm 6.9$)$ days vs. $(23.1 \pm 7.6)$ days, $P=0.007$ ] and a reduced hospital length of stay $[(23.9 \pm 7.1)$ days vs. $(27.7 \pm 3.1)$ days, $P<0.001]$. No significant difference was found in 30-day mortality between the BIA and TRD groups.

\section{Discussion}

Currently, the fluid resuscitation strategy among postinjury OA patients in the ICU is predominantly guided by traditional protocols. Several retrospective studies of fluid resuscitation therapy have been implemented to achieve PFC and better outcomes among OA patients $[20,23]$. However, no RCTs have supported the efficacy of rational fluid therapy for the prevention of FO and promotion of PFC in OA patients. To the best of our knowledge, this was the first randomized trial to use a multifrequency BIA device in an ICU setting to guide fluid resuscitation with a simplified protocol. The principal finding of the BGFM trial was that among ICU patients with $\mathrm{OA}$, a postoperative fluid resuscitation regimen with adjustment determined by BIA resulted in a higher PFC rate, decreased FO, and lower complication rate than a traditional resuscitation strategy according to the usual clinical parameters.

Optimizing postoperative fluid therapy to promote PFC by alleviating fluid overload remains a challenge. Frequent development of FO in OA patients cannot be detected on time and that the degree of hydration cannot be appropriately assessed with effective measures. However, BIA, as promising tools, can be used to measure the body composition and fluid volume with an 
Table 3 Generalized linear regression analysis of time to fascial closure, and cumulative fluid balance

\begin{tabular}{|c|c|c|c|c|c|c|}
\hline \multirow[t]{2}{*}{ Group } & \multicolumn{2}{|c|}{ Time to fascial closure } & \multirow[t]{2}{*}{$P$} & \multicolumn{2}{|c|}{ Cumulative fluid balance } & \multirow[t]{2}{*}{$P$} \\
\hline & $\beta$ coefficient & Standard error & & Bcoefficient & Standard error & \\
\hline BIA vs. TRD & -3.66 & 0.49 & $<0.001$ & -6632.80 & 746.91 & $<0.001$ \\
\hline
\end{tabular}

Adjusted for age, male, BMI, severity of illness (mechanism of injury, AIS, ISS, APACHE II and SOFA score), indications, number of reoperations, number of vasopressors and intraoperative fluid volume. BIA bioelectrical impedance analysis, TRD traditional fluid resuscitation. $P$-values less than 0.05 were considered as statistically significant

electric current transmitted through the body and has been validated in patients [38-40]. Our SICU began using this technology in 2008 and confirmed that it was reliable and easy to use for bedside evaluation [41]. In the current study, BIA was examined as a safe and effective technology in postinjury OA patients during ICU resuscitation.

Reduced fluid overload is an advantage of resuscitation directed by BIA. As an instantaneous technique to measure changes in the body fluid status of ICU patients, BIA can reflect the fluid overload state earlier and bypass errors due to fluid balance accounting. Additionally, serial BIA measurements accurately quantify the degree of edema, which establishes a target value to guide optimized fluid therapy and treatment targets for diuretics or ultrafiltration for CRRT patients. With the intervention based on the BIA protocol, an adequate circulating blood volume could be established, and complications resulting from fluid removal might be prevented. In a nutshell, BIA technique improved detection of the fluid
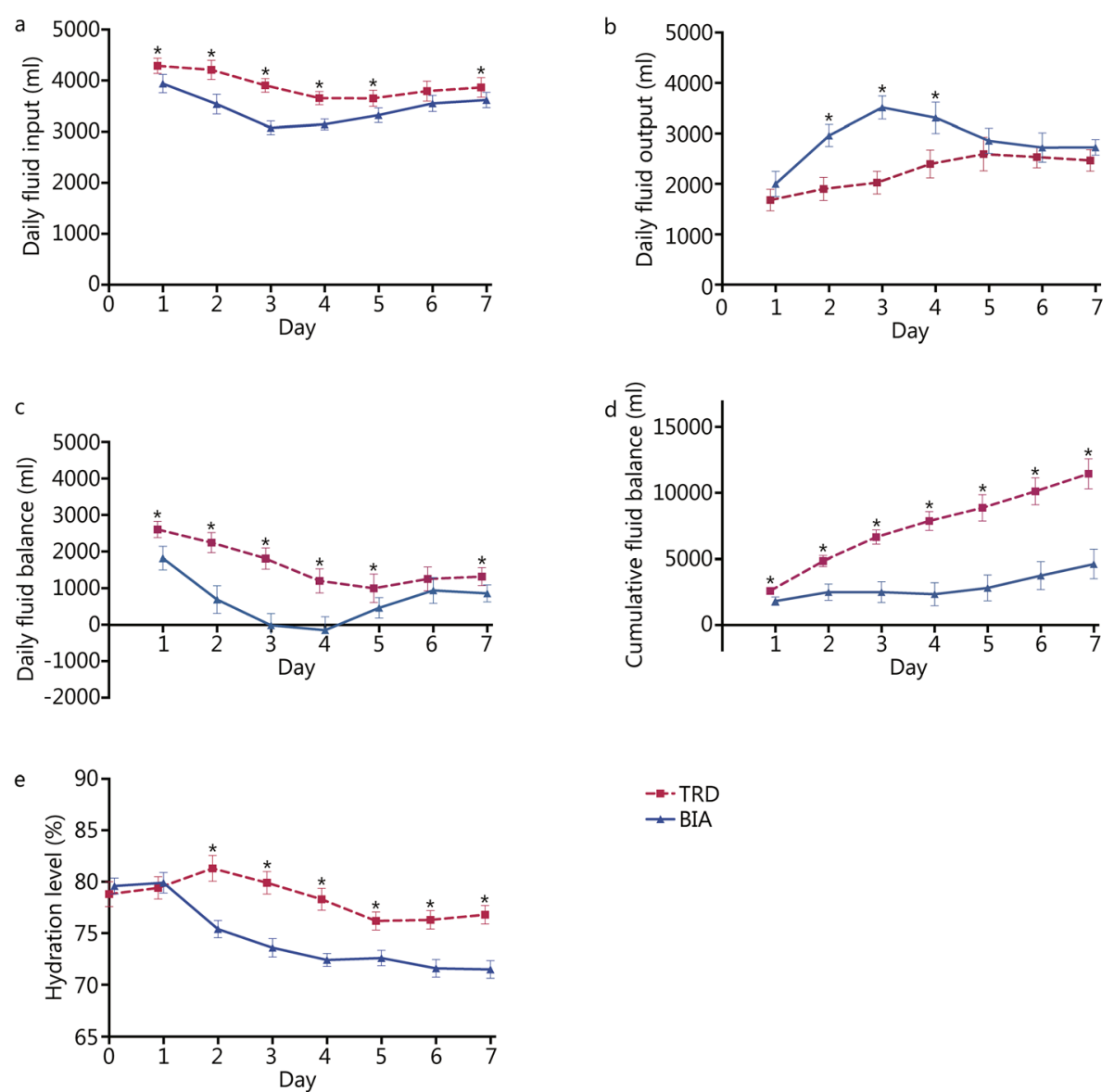

Fig. 5 Time course of fluid resuscitation variables. a Daily fluid input. b Daily fluid output. c Daily fluid balance. d Cumulative fluid balance. e Hydration level. Means and 95\% confidence intervals of pertinent variables for the first week after ICU admission. The fluid volume and bioelectrical impedance analysis variables of the BIA group are depicted with a blue full line, and those of the TRD group are depicted with a red dotted line. ${ }^{*} P<0.05$, day-by-day pairwise comparison between the BIA and TRD groups. BIA bioelectrical impedance analysis, ECMO extracorporeal membrane oxygenator 
overload state and guided optimized therapy, thereby preventing fluid overload in $\mathrm{OA}$ patients during resuscitation.

Notably, the application of the BIA technique was associated with an increased primary fascial closure rate and earlier fascial closure. Goussous and colleagues reported that a smaller fluid balance over the first 10 days was associated with PFC success among nontrauma patients [15]. Recently, we reported that fluid volume overload negatively influenced fascial closure among OA patients [26]. For the first time in ICU resuscitation practice, we combined BIA technology with a judicious fluid resuscitation protocol. The improved PFC rate in the BIA group was speculated to reduce FO and avoid massive visceral edema compared with those of the TRD protocol based on fluid balance registration in the ICU. Some studies reported PFC rates of $70 \%$ or higher using VAWCM, however, the PFC rate of trauma patients with severe intra-abdominal infection (sIAI) was much lower than other studies (35\% vs. $90 \%$ ). Padalino and colleagues reported that the PFC rate was only $33-60 \%$ in OA patients with sIAI. Many of the patients admitted to our referral center were severely injured accompanying sIAI transferred from local hospitals, and therefore showed a lower rate of PFC in TRD group. In this trial, the application of the BIA technique in ICU resuscitation significantly promoted PFC, which presented an encouraging result.

In the present study, the use of BIA was associated with a decreased incidence of adverse events, particularly EAF. Large volume resuscitation was associated with an increased frequency of complications, such as fistula formation, longer time to recovery from intestinal edema, and higher mortality [7]. Miller et al. [42] reported that fascial closure within 8 days contributed to fewer complications and better outcomes. Other studies using dynamic indices, better temporary abdominal closure dressings, and adjunctive peritoneal resuscitation decreased the time to primary fascial closure and improved the outcomes [33, 43, 44]. More significant primary fascial closure and fewer severe complications were shown for patients with BIA-directed fluid therapy. EAF is a disastrous intra-abdominal complication [45, 46], whose formation prevents OA patients from achieving PFC. We hypothesize that this decrease of EAF formation in BIA group was related to the promoted PFC and subsequently decreased the incidence and time of visceral exposure.

This study has several limitations. First of all, weightbased methods to determine the fluid overload status were not studied in this trial. Moreover, obesity, the size of the abdominal incision, the effect of intra-abdominal pressure on CVP, and other accompanying conditions might be important factors that we failed to control.
Furthermore, we did not compare BIA-guided fluid resuscitation with other restrictive fluid management, and future prospective studies should be implemented to solidify the clinical results. Besides, problems inherent in the nature of this single-center study limit the generalizability of the research results to a broader population. Therefore, multicenter trials with a broader spectrum, including the use of BIA technique in balanced resuscitation practices may be sufficient to answer more critical clinical questions.

\section{Conclusions}

Among postinjury OA patients in the ICU, the application of fluid resuscitation protocols with adjustments determined according to hydration level measured by BIA compared with the traditional fluid resuscitation strategy determined by the treating clinicians according to the usual clinical parameters resulted in higher PFC rates and fewer severe complications. Thus, close monitoring of the hydration status with the BIA technique may be routinely used in postinjury OA patients.

\begin{abstract}
Abbreviations
ACS: Abdominal compartment syndrome; AIS: Abbreviated injury score: ALI: Acute lung injury; APACHE II: Acute physiology and chronic health evaluation II; BIA: Bioelectrical impedance analysis; BMI: Body mass index; Cls: Confidence intervals; CFB: Cumulative fluid balance; CRRT: Continuous renal replacement therapy; CVP: Central venous pressure; DCS: Damage control surgery; EAF: Enteroatmospheric fistula; ECMO: extracorporeal membrane oxygenator; EN: Enteral nutrition; FM: Fat mass; FO: Fluid overload; HL: Hydration level; ICU: Intensive care unit; ISS: Injury severity score; LOS: Length of stay; MAP: Mean arterial pressure; NYHA: New York heart association; OA: Open abdomen; PFC: Primary fascial closure;

POD: Postoperative day; R: Resistance; RCT: Randomized controlled trial; SAS: Statistical analysis system; SD: Standard deviation; sIAI: Severe intraabdominal infection; SICU: Surgical intensive care unit; SOFA: Sequential organ failure assessment; TAC: Temporary abdominal closure; TRD: Traditional fluid resuscitation; VAWCM: Vacuum-assisted and mesh-mediated fascial traction; Xc: Reactance
\end{abstract}

\section{Supplementary Information}

The online version contains supplementary material available at https://doi. org/10.1186/s40779-021-00329-0.

Additional file 1: Table S1 Intraoperative and postoperative fluid volume and drug management. BIA bioelectrical impedance analysis, TRD traditional fluid resuscitation, POD postoperative day.

\section{Acknowledgements}

The authors thank Xue-Feng Lai for his invaluable support in performing the analysis.

\section{Authors' contributions}

KW, SS and WD designed the study. SS, XW, CC, ZD, and CY enrolled patients and collected data. KW, SS, and BL performed the analysis and made the Figs. KW and WD drafted and revised the manuscript. WL and JL helped revise the manuscript. All authors critically reviewed the manuscript. All authors read and approved the final manuscript.

\section{Funding}

This work was supported by grants from the National Natural Science Foundation of China (Grant No. 81770532, WD) and the Jiangsu Province Medical Foundation for Youth Talents (Grant No. QNRC2016901, WD). 


\section{Availability of data and materials}

The datasets used and analysed during the current study are available from the corresponding author on reasonable request.

\section{Declarations}

\section{Ethics approval and consent to participate}

This study was approved by the Institutional Ethics Committee of Jinling Hospital, Medical School of Nanjing University (No. 2012NZGKJ-096).

\section{Consent for publication}

Not applicable.

\section{Competing interests}

The authors declare that they have no competing interests.

\section{Author details}

'Division of Trauma and Surgical Intensive Care Unit, Research Institute of General Surgery, Jinling Hospital, Medical School of Nanjing University, Nanjing 210002, No. 305 East Zhongshan Road, Nanjing 210002, Jiangsu, China. ${ }^{2}$ Division of Trauma and Surgical Intensive Care Unit, Research Institute of General Surgery, The First School of Clinical Medicine, Southern Medical University, Nanjing 210002, Jiangsu, China.

\section{Received: 25 April 2020 Accepted: 27 May 2021}

Published online: 07 June 2021

\section{References}

1. Roberts DJ, Ball CG, Feliciano DV, Moore EE, Ivatury RR, Lucas CE, et al. History of the innovation of damage control for management of trauma patients: 1902-2016. Ann Surg. 2017;265(5):1034-44. https://doi.org/10.1097/ SLA.0000000000001803.

2. Balogh ZJ, Lumsdaine W, Moore EE, Moore FA. Postinjury abdominal compartment syndrome: from recognition to prevention. Lancet. 2014; 384(9952):1466-75. https://doi.org/10.1016/S0140-6736(14)61689-5.

3. Rogers WK, Garcia L. Intraabdominal hypertension, abdominal compartment syndrome, and the open abdomen. Chest. 2018;153(1):238-50. https://doi. org/10.1016/j.chest.2017.07.023

4. Sava J, Alam HB, Vercruysse G, Martin M, Brown CVR, Brasel K, et al. Western trauma association critical decisions in trauma: management of the open abdomen after damage control surgery. J Trauma Acute Care Surg. 2019; 87(5):1232-8. https://doi.org/10.1097/TA.0000000000002389.

5. Cheatham ML, Safcsak K, Brzezinski SJ, Lube MW. Nitrogen balance, protein loss, and the open abdomen. Crit Care Med. 2007;35(1):127-31. https://doi. org/10.1097/01.CCM.0000250390.49380.94.

6. Dubose JJ, Scalea TM, Holcomb JB, Shrestha B, Okoye O, Inaba K, et al. Open abdominal management after damage-control laparotomy for trauma: a prospective observational American Association for the Surgery of Trauma multicenter study. J Trauma Acute Care Surg. 2013;74(1):113-20; discussion 1120-2. https://doi.org/10.1097/TA.0b013e31827891ce.

7. Bradley MJ, Dubose JJ, Scalea TM, Holcomb JB, Shrestha B, Okoye O, et al. Independent predictors of enteric fistula and abdominal sepsis after damage control laparotomy: results from the prospective AAST open abdomen registry. JAMA Surg. 2013;148(10):947-54. https://doi.org/10.1001/ jamasurg.2013.2514

8. Fox N, Crutchfield M, Lachant M, Ross SE, Seamon MJ. Early abdominal closure improves long-term outcomes after damage-control laparotomy. J Trauma Acute Care Surg. 2013;75(5):854-8. https://doi.org/10.1097/TA.0b013 e3182a8fe6b.

9. Coccolini F, Roberts D, Ansaloni L, Ivatury R, Gamberini E, Kluger Y, et al. The open abdomen in trauma and non-trauma patients: WSES guidelines. World J Emerg Surg. 2018;13(1):7. https://doi.org/10.1186/s13017-018-0167-4.

10. Madigan MC, Kemp CD, Johnson JC, Cotton BA. Secondary abdominal compartment syndrome after severe extremity injury: are early, aggressive fluid resuscitation strategies to blame? J Trauma. 2008;64(2):280-5. https:// doi.org/10.1097/TA.0b013e3181622bb6.

11. Holodinsky JK, Roberts DJ, Ball CG, Blaser AR, Starkopf J, Zygun DA, et al. Risk factors for intra-abdominal hypertension and abdominal compartment syndrome among adult intensive care unit patients: a systematic review and meta-analysis. Crit Care. 2013;17(5):R249. https://doi.org/10.1186/cc13 075 .
12. Hatch QM, Osterhout LM, Ashraf A, Podbielski J, Kozar RA, Wade CE, et al. Current use of damage-control laparotomy, closure rates, and predictors of early fascial closure at the first take-back. J Trauma. 2011;70(6):1429-36. https://doi.org/10.1097/TA.0b013e31821b245a.

13. Lambertz A, Mihatsch C, Roth A, Kalverkamp S, Eickhoff R, Neumann UP, et al. Fascial closure after open abdomen: initial indication and early revisions are decisive factors--a retrospective cohort study. Int J Surg. 2015; 13:12-6. https://doi.org/10.1016/j.jjsu.2014.11.025.

14. Cristaudo AT, Jennings SB, Hitos K, Gunnarsson R, Decosta A. Treatments and other prognostic factors in the management of the open abdomen: a systematic review. J Trauma Acute Care Surg. 2017;82(2):407-18. https://doi. org/10.1097/TA.0000000000001314.

15. Goussous N, Kim BD, Jenkins DH, Zielinski MD. Factors affecting primary fascial closure of the open abdomen in the nontrauma patient. Surgery, 2012;152(4):777-83; discussion 783-4. https://doi.org/10.1016/j.surg.2012.07. 015.

16. Samoni S, Vigo V, Resendiz LI, Villa G, De Rosa S, Nalesso F, et al. Impact of hyperhydration on the mortality risk in critically ill patients admitted in intensive care units: comparison between bioelectrical impedance vector analysis and cumulative fluid balance recording. Crit Care. 2016;20(1):95. https://doi.org/10.1186/s13054-016-1269-6.

17. Van Haren F. Personalised fluid resuscitation in the ICU: still a fluid concept? Crit Care. 2017;21 (Suppl 3):313. https://doi.org/10.1186/s13054-017-1909-5.

18. Holcomb JB, Del Junco DJ, Fox EE, Wade CE, Cohen MJ, Schreiber MA, et al. The prospective, observational, multicenter, major trauma transfusion (PROMMTT) study: comparative effectiveness of a time-varying treatment with competing risks. JAMA Surg. 2013;148(2):127-36. https://doi.org/10.1 001/2013.jamasurg.387.

19. Cantle PM, Cotton BA. Balanced resuscitation in trauma management. Surg Clin North Am. 2017;97(5):999-1014. https://doi.org/10.1016/j.suc.2017.06. 002.

20. Cotton BA, Reddy N, Hatch QM, Lefebvre E, Wade CE, Kozar RA, et al. Damage control resuscitation is associated with a reduction in resuscitation volumes and improvement in survival in 390 damage control laparotomy patients. Ann Surg. 2011;254(4):598-605. https://doi.org/10.1097/SLA.0b013 e318230089e.

21. Duke MD, Guidry C, Guice J, Stuke L, Marr AB, Hunt JP, et al. Restrictive fluid resuscitation in combination with damage control resuscitation: time for adaptation. J Trauma Acute Care Surg. 2012;73(3):674-8. https://doi.org/10.1 097/TA.0b013e318265ce1f

22. Loftus TJ, Efron PA, Bala TM, Rosenthal MD, Croft CA, Smith RS, et al. Hypertonic saline resuscitation after emergent laparotomy and temporary abdominal closure. J Trauma Acute Care Surg. 2018;84(2):350-7. https://doi. org/10.1097/TA.0000000000001730.

23. Ghneim MH, Regner JL, Jupiter DC, Kang F, Bonner GL, Bready MS, et al. Goal directed fluid resuscitation decreases time for lactate clearance and facilitates early fascial closure in damage control surgery. Am J Surg. 2013; 206(6):995-9; discussion 9-1000. https://doi.org/10.1016/j.amjsurg.2013.07. 021.

24. Harvin JA, Mims MM, Duchesne JC, Cox CS Jr, Wade CE, Holcomb JB, et al. Chasing 100\%: the use of hypertonic saline to improve early, primary fascial closure after damage control laparotomy. J Trauma Acute Care Surg. 2013; 74(2):426-30; discussion 431-2. https://doi.org/10.1097/TA.0b013e31827e2a 96.

25. Smith JW, Garrison RN, Matheson PJ, Franklin GA, Harbrecht BG, Richardson JD. Direct peritoneal resuscitation accelerates primary abdominal wall closure after damage control surgery. J Am Coll Surg. 2010;210(5):658-64, 64-7. https://doi.org/10.1016/j.jamcollsurg.2010.01.014.

26. Huang $Q$, Zhao R, Yue C, Wang W, Zhao Y, Ren J, et al. Fluid volume overload negatively influences delayed primary facial closure in open abdomen management. J Surg Res. 2014;187(1):122-7. https://doi.org/10.1 016/j.jss.2013.09.032.

27. Eastwood GM. Evaluating the reliability of recorded fluid balance to approximate body weight change in patients undergoing cardiac surgery. Heart Lung. 2006;35(1):27-33. https://doi.org/10.1016/j.hrtlng.2005.06.001.

28. Perren A, Markmann M, Merlani G, Marone C, Merlani P. Fluid balance in critically ill patients. Should we really rely on it? Minerva Anestesiol. 2011; 77(8):802-11.

29. Cordemans C, De Laet I, Van Regenmortel N, Schoonheydt K, Dits H, Huber W, et al. Fluid management in critically ill patients: the role of extravascular lung water, abdominal hypertension, capillary leak, and fluid balance. Ann 
Intensive Care. 2012;2(Suppl 1):S1. https://doi.org/10.1186/2110-5820-2-S1S1.

30. Moissl UM, Wabel P, Chamney PW, Bosaeus I, Levin NW, Bosy-Westphal A, et al. Body fluid volume determination via body composition spectroscopy in health and disease. Physiol Meas. 2006;27(9):921-33. https://doi.org/10.1 088/0967-3334/27/9/012

31. Malbrain ML, Huygh J, Dabrowski W, De Waele JJ, Staelens A, Wauters J. The use of bio-electrical impedance analysis (BIA) to guide fluid management, resuscitation and deresuscitation in critically ill patients: a bench-to-bedside review. Anaesthesiol Intensive Ther. 2014;46(5):381-91. https://doi.org/10. 5603/AIT.2014.0061.

32. Samoni S, Vigo V, Resendiz LIB, Villa G, De Rosa S, Nalesso F, et al. Impact of hyperhydration on the mortality risk in critically ill patients admitted in intensive care units: comparison between bioelectrical impedance vector analysis and cumulative fluid balance recording. Crit Care. 2016;20:8.

33. Kirkpatrick AW, Roberts DJ, Faris PD, Ball CG, Kubes P, Tiruta C, et al. Active negative pressure peritoneal therapy after abbreviated laparotomy: the intraperitoneal vacuum randomized controlled trial. Ann Surg. 2015;262(1): 38-46. https://doi.org/10.1097/SLA.0000000000001095.

34. Rasilainen SK, Mentula PJ, Leppaniemi AK. Vacuum and mesh-mediated fascial traction for primary closure of the open abdomen in critically ill surgical patients. Br J Surg. 2012;99(12):1725-32. https://doi.org/10.1002/bjs. 8914.

35. Boele Van Hensbroek P, Wind J, Dijkgraaf MG, Busch OR, Goslings JC. Temporary closure of the open abdomen: a systematic review on delayed primary fascial closure in patients with an open abdomen. World I Surg. 2009;33(2):199-207. https://doi.org/10.1007/s00268-008-9867-3.

36. Valle R, Aspromonte N, Milani L, Peacock FW, Maisel AS, Santini M, et al. Optimizing fluid management in patients with acute decompensated heart failure (ADHF): the emerging role of combined measurement of body hydration status and brain natriuretic peptide (BNP) levels. Heart Fail Rev. 2011;16(6):519-29. https://doi.org/10.1007/s10741-011-9244-4.

37. Carlson GL, Patrick H, Amin Al, Mcpherson G, Maclennan G, Afolabi E, et al. Management of the open abdomen: a national study of clinical outcome and safety of negative pressure wound therapy. Ann Surg. 2013;257(6): 1154-9. https://doi.org/10.1097/SLA.0b013e31828b8bc8.

38. Chen HY, Wu BY, Gong DH, Liu ZH. Fluid overload at start of continuous renal replacement therapy is associated with poorer clinical condition and outcome: a prospective observational study on the combined use of bioimpedance vector analysis and serum $\mathrm{N}$-terminal pro-B-type natriuretic peptide measurement. Crit Care. 2015;19(1):135.

39. Piccoli A. Italian C-BlaSG. Bioelectric impedance vector distribution in peritoneal dialysis patients with different hydration status. Kidney Int. 2004 65(3):1050-63. https://doi.org/10.1111/j.1523-1755.2004.00467.x.

40. Donadio C, Consani C, Ardini M, Bernabini G, Caprio F, Grassi G, et al. Estimate of body water compartments and of body composition in maintenance hemodialysis patients: comparison of single and multifrequency bioimpedance analysis. J Ren Nutr. 2005;15(3):332-44. https://doi.org/10.1016/j.jrn.2005.04.001.

41. Gong J, Zuo L, Guo Z, Zhang L, Li Y, Gu L, et al. Impact of disease activity on resting energy expenditure and body composition in adult crohn's disease: a prospective longitudinal assessment. JPEN J Parenter Enteral Nutr. 2015:39(6):713-8. https://doi.org/10.1177/0148607114528360.

42. Miller RS, Morris JA Jr, Diaz JJ Jr, Herring MB, May AK. Complications after 344 damage-control open celiotomies. J Trauma. 2005;59(6):1365-71; discussion 1371-4,. https://doi.org/10.1097/01.ta.0000196004.49422.af.

43. Bradley M, Galvagno S, Dhanda A, Rodriguez C, Lauerman M, Dubose J, et al. Damage control resuscitation protocol and the management of open abdomens in trauma patients. Am Surg. 2014;80(8):768-75. https://doi.org/1 $0.1177 / 000313481408000825$

44. Smith JW, Matheson PJ, Franklin GA, Harbrecht BG, Richardson JD, Garrison RN. Randomized controlled trial evaluating the efficacy of peritoneal resuscitation in the management of trauma patients undergoing damage control surgery. J Am Coll Surg. 2017;224(4):396-404. https://doi.org/10.101 6/j.jamcollsurg.2016.12.047.

45. Teixeira PG, Inaba K, Dubose J, Salim A, Brown C, Rhee P, et al. Enterocutaneous fistula complicating trauma laparotomy: a major resource burden. Am Surg. 2009;75(1):30-2. https://doi.org/10.1177/0003134 80907500106

46. Diaz JJ Jr, Dutton WD, Ott MM, Cullinane DC, Alouidor R, Armen SB, et al. Eastern association for the surgery of trauma: a review of the management of the open abdomen--part 2 "management of the open abdomen". J Trauma. 2011;71(2):502-12. https://doi.org/10.1097/TA.0b013e318227220c.

\section{Ready to submit your research? Choose BMC and benefit from:}

- fast, convenient online submission

- thorough peer review by experienced researchers in your field

- rapid publication on acceptance

- support for research data, including large and complex data types

- gold Open Access which fosters wider collaboration and increased citations

- maximum visibility for your research: over $100 \mathrm{M}$ website views per year

At BMC, research is always in progress.

Learn more biomedcentral.com/submissions 